11

\title{
Люминесцентные свойства гибридных наноструктур на основе квантовых точек CdS, 1,3-дикетоната европия и молекул метиленового голубого
}

\author{
(C) М.С. Смирнов ${ }^{1}$, О.В. Овчинников ${ }^{19}$, И.В. Тайдаков ${ }^{2,3,4}$, С.А. Амброзевич ${ }^{2,4}$, \\ А.Г. Витухновский ${ }^{2,4,5}$, А.И. Звягин ${ }^{1}$, Г.К. УСков ${ }^{1}$ \\ ${ }^{1}$ Воронежский государственный университет, \\ 394018 Воронеж, Россия \\ ${ }^{2}$ Физический институт им П.Н. Лебедева РАН, \\ 119991 Москва, Россия \\ ${ }^{3}$ Российский химико-технологический университет им. Д.И. Менделеева, \\ 125047 Москва, Россия \\ ${ }^{4}$ Московский фризико-технический институт (государственный университет), \\ 141701 Долгопрудный, Россия \\ ${ }^{5}$ Национальный исследовательский ядерный университет „МИФИ“, \\ 115409 Москва, Россия \\ ฯ e-mail: smirnov_m_s@mail.ru
}

Поступила в редакцию 02.03.2018 г.

Обсуждены люминесцентные свойства гибридных наноструктур, построенных из коллоидных квантовых точек (KT) CdS, пасивированных тиогликолевой кислотой, трис-(теноилтрифторацетоната) европия (III) и молекул красителя метиленового голубого. Обнаружены спектральные признаки формирования КТ типа ядро/оболочка $\mathrm{CdS} / \mathrm{CdS}: \mathrm{Eu}^{3+}$. Отмечена вероятность адсорбции комплекса европия на интерфейсах КТ и формирования KT $\mathrm{CdS} / \mathrm{TGA} / \mathrm{Eu}^{3+}$. Получены спектральные закономерности, демонстрирующие безызлучательный перенос энергии от центров рекомбинационной люминесценции КТ $\mathrm{CdS}$ к ионам $\mathrm{Eu}^{3+} \mathrm{B}^{3}$ структурах $\mathrm{CdS} / \mathrm{CdS}: \mathrm{Eu}^{3+}$ и $\mathrm{CdS} / \mathrm{TGA} / \mathrm{Eu}^{3+}$, проявляющиеся в тушении рекомбинационной люминесценции КТ и разгорании внутрицентровой люминесценции $\mathrm{Eu}^{3+}$, усиливающимся с ростом концентрации комплекса европия. При ассоциации таких структур с молекулами метиленового голубого обнаружено увеличение полуширины спектров его поглощения на $10-15 \%$ при неизменном положении максимума полосы поглощения. С увеличением концентрации молекул метиленового голубого наблюдали падение интенсивности как рекомбинационной полосы люминесценции КT CdS с длиной волны $530 \mathrm{~nm}$, так и люминесценции ионов $\mathrm{Eu}^{3+}$ и одновременное разгорание флуоресценции метиленового голубого с длиной волны около $675 \mathrm{~nm}$. При этом наблюдали падение времени жизни люминесценции в полосах КТ и ионов европия. Сделан вывод о безызлучательном переносе энергии возбуждения как от центров рекомбинационной люминесценции, так и от ионов $\mathrm{Eu}^{3+}$ к молекулам метиленового голубого.

DOI: $10.21883 / \mathrm{OS} .2018 .08 .46367 .65-18$

\section{Введение}

Полупроводниковые кристаллы, а также диэлектрики, легированные редкоземельными элементами, находят обширные применения в качестве твердотельных лазеров, волоконных усилителей $[1,2]$, биометок $[3,4]$, солнечных элементов [5] и других оптоэлектронных устройств [6,7]. Ключевым является высокий квантовый выход люминофоров на основе ионов редкоземельных элементов (РЗЭ) [8-13]. В силу того, что существенную роль в оптических свойствах РЗЭ играет окружение или матрица, в которую они помещены, значительный интерес представляет легирование редкоземельными ионами нанокристаллов размерами порядка боровского радиуса экситона Ванье-Мотта (квантовых точек, КТ), обладающих размерной зависимостью их абсорбционных и люминесцентных свойств [14-17]. В таких объектах возможна не только аддитивность свойств КТ и редкоземельных ионов, часть переходов в которых имеет высокий квантовый выход, но и возникновение гибридных свойств, связанных с обменом электронными возбуждениями между указанными компонентами.

Особое место в качестве легирующей примеси занимают ионы европия $\mathrm{Eu}^{3+}$, поскольку для них имеются узкие пики люминесценции в красной области (вблизи $615 \mathrm{~nm})$ [14-16], а также характерен магнитный отклик [17]. Дополнительной функционализации КТ, легированных ионами $\mathrm{Eu}^{3+}$, можно достигать сопряжением их с молекулами органических красителей. В гибридных наноструктурах подобного рода вероятно возникновение оптических свойств, обусловленных существованием нескольких каналов распада электронных возбуждений. Ключевой проблемой здесь является механизм формирования, переноса и деградации возбуждений с участием $\mathrm{Eu}^{3+}$, молекул красителей и КТ. К настоящему времени подобные ситуации не рассматривались. Имеются лишь отдельные работы, направленные на выяснение условий для встраивания ионов $\mathrm{Eu}^{3+}$ в КТ и механизма 
возбуждения их интенсивной люминесценции [18-22]. Также недостаточно рассмотрена проблема взаимодействия центров рекомбинационной люминесценции КТ и ионов $\mathrm{Eu}^{3+}$, встроенных в КТ. Предполагается, например, перенос электронного возбуждения от центров рекомбинации кристаллов $\mathrm{ZnO}$ к ионам $\mathrm{Eu}^{3+}$ [23].

Для ассоциатов КТ с молекулами красителей довольно подробно исследованы закономерности резонансного безызлучательного обмена электронными возбуждениями между молекулами красителей и экситонами КТ [24-26], а также центрами рекомбинационной люминесценции [27-35].

В свою очередь перенос энергии в комплексах из ионов РЗЭ и молекул красителей рассмотрен как для случаев, когда Р3Э выступают тушителями люминесценции красителя, так и наоборот [36-43]. Обращено внимание на сильные акцептирующие свойства $\mathrm{Eu}^{3+}$ и возможность фотореакции в комплексах с красителями с фотопереносом электрона [44]. На возможность диполь-дипольного переноса от РЗЭ к молекулам красителей указано в работах [38-40]. При этом имеются исследования, свидетельствующие в пользу обменнорезонансного переноса энергии на триплетный уровень красителей $[36,40,41]$. В настоящее время большое внимание уделяется исследованиям для наночастиц (НЧ), собранных из различных комплексов РЗЭ, в том числе дикетонатов редкоземельных ионов и молекул красителей [42-46].

Приведенный краткий анализ ситуации в данной области свидетельствуют о том, что закономерности обмена электронными возбуждениями в ассоциатах коллоидных КТ, легированных ионами РЗЭ, в том числе $\mathrm{Eu}^{3+}$, с молекулами красителей пока не установлены. В настоящей работе рассматриваются закономерности люминесцентных свойств гибридных наноструктур, построенных из коллоидных КT $\mathrm{CdS}$, пассивированных тиогликолевой кислотой, $\beta$-дикетоната европия и молекул катионного органического красителя метиленового голубого $\left(\mathrm{MB}^{+}\right)$.

\section{Методы исследования и образцы}

\section{Методики и аппаратура исследований}

Спектры оптического поглощения исследовали в УФ и видимой областях в диапазоне от 200 до $1000 \mathrm{~nm} \mathrm{c}$ помощью волоконного спектрометра USB2000+ (Ocean Optics USA) с источником излучения USB-DT (Ocean Optics USA). Спектры фотолюминесценции (ФЛ) и время-разрешенную люминесценцию исследовали с помощью USB2000+ и платы время-коррелированного однофотонного счета TimeHarp 260 (PicoQuant Germany) с модулем ФЭУ РМС-100-20 (Becker\&Hickl Germany) с временным разрешением, составляющим 0.2 ns. Образцы возбуждали УФ излучением импульсного полупроводникового лазера Alphalas PLDD-250 (Alphalas Germany) с длиной волны $375 \mathrm{~nm}$, длительностью $60 \mathrm{ps}$ и частотой повторения импульсов $100 \mathrm{kHz}$ или $300 \mathrm{~Hz}$. Также для возбуждения люминесценции использовали полупроводниковый излучающий диод с длиной волны $375 \mathrm{~nm}$ и оптической мощностью 50 мВт (RF-UVXC35LN-UF REFOND China).

Структурные исследования выполнены на просвечивающем электронном микроскопе (ПЭМ) Libra120 (CarlZeiss, Germany, ЦКП ФГБОУ ВО ВГУ) и рентгеновском дифрактометре ARL X'TRA (Switzerland, ЦКП ФГБОУ ВО ВГУ) для $K_{\alpha 1}$-линии меди.

\section{Образцы для исследований}

Коллоидные KT CdS, стабилизированные тиогликолевой кислотой (TGA), синтезированы по разработанной ранее методике, описанной в работах $[47,48]$. Для синтеза $\mathrm{CdS} / \mathrm{TGA}$ использовали раствор прекурсора $\mathrm{Cd}^{2+} / \mathrm{TGA}$, полученный смешиванием $\mathrm{CdBr}_{2}(1.3 \mathrm{mmol})$ и TGA (2.6 mmol). Бромид кадмия растворяли в воде $(200 \mathrm{ml})$ и добавляли TGA. Далее при интенсивном перемешивании в стакан каплями добавляли $\mathrm{NaOH}$ $(1 \mathrm{M})$ и доводили значение показателя $\mathrm{pH}$ раствора до 7. В приготовленный раствор $\mathrm{Cd}^{2+} / \mathrm{TGA}$ быстро доливали $50 \mathrm{ml}$ водного раствора $\mathrm{Na}_{2} \mathrm{~S}(1.3 \mathrm{mmol})$. В синтезированные таким образом КT CdS добавляли ацетон до 50\% раствора, центрифугировали и повторно растворяли в бидистилированной воде. Процедуру очистки повторяли несколько раз. Для исследования центрифугированные KT CdS растворяли в малом количестве воды и выливали в этанол так, чтобы содержание этанола в растворе понижалось не более чем на $1-2 \%$.

Исследование рентгеновской дифракции (XRD) показало формирование нанокристаллов $\mathrm{CdS}$ в кубической решетке. Анализ ТЕМ-изображений свидетельствует об образовании отдельных наночастиц CdS. Размеры исследуемых образцов коллоидных КТ, полученные при анализе ТЕМ-изображений - диаметр нанокристаллов $d=3 \pm 0.2 \mathrm{~nm}$, подтвердили данные XRD. Результаты морфологических исследований подробно обсуждаются в работах $[47,48]$ и полностью аналогичны.

Раствор дикетоната европия приготавливали из хлорида европия и 4, 4, 4-трифтор-1-(тиофен-2-ил)бутан1,3-диона (теноилтрифторацетона). Хлорид европия $(10 \mathrm{mmol})$ растворяли в смеси воды и этанола $200 \mathrm{ml}$. Далее к перемешиваемому теплому $\left(40^{\circ} \mathrm{C}\right)$ раствору добавляли (30 mmol) лиганда, а затем $10 \mathrm{ml}(30 \mathrm{mmol})$ водного раствора $\mathrm{NaOH}$ до повышения $\mathrm{pH}$ до 6.8. Смесь нагревали при $50^{\circ} \mathrm{C}$ в течение $4 \mathrm{~h}$ в закрытой колбе и охлаждали. Для дальнейших исследований полученный осадок растворяли в этаноле.

Легирование KT CdS дикетонатом европия осуществляли путем введения в коллоидный раствор с КТ на стадии их кристаллизации соответствующего этанольного раствора. Такой прием обеспечивает создание нанокристаллов $\mathrm{CdS}$ и последующую доставку ионов европия на интерфейс растущих КТ, избегая образования гидроксида европия. В итоге концентрация смеси КТ $\mathrm{CdS}$ и дикетоната европия составляла $10^{-5} \mathrm{~mol} / \mathrm{l}$. 


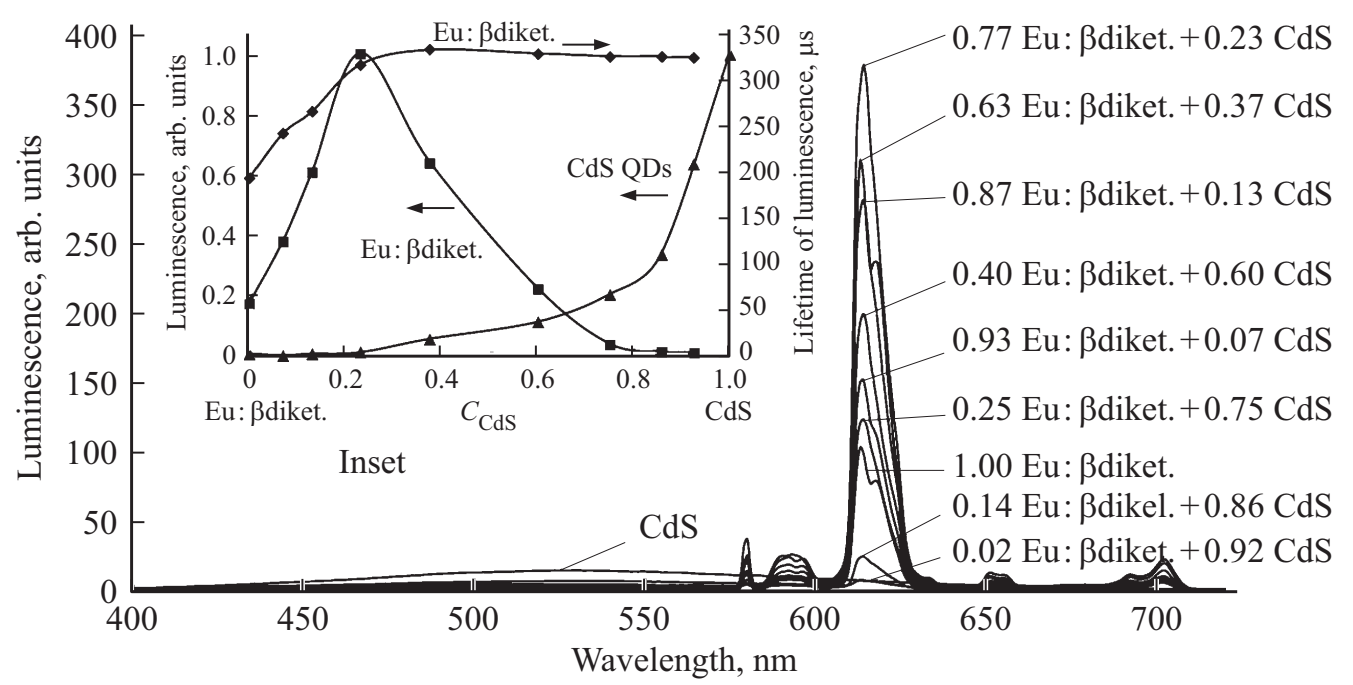

Рис. 1. Спектры люминесценции смесей КT CdS и дикетоната европия в зависимости от соотношения компонентов. На врезке зависимость интенсивности люминесценции $\mathrm{Eu}^{3+}$ и KT CdS от относительной концентрации KT CdS в растворе.

Гибридные ассоциаты из комплексов КT $\mathrm{CdS}$ и дикетоната европия с молекулами $\mathrm{MB}^{+}$приготавливали введением этанольного раствора красителя в коллоидный раствор. Концентрация красителя $C_{\text {Кр }}$ составляла $10^{-4}-10^{-2} \mathrm{~mol} \mathrm{MB}{ }^{+} / \mathrm{mol} \mathrm{KT} \mathrm{CdS}$ (далее m.d.).

\section{Результаты и обсуждение}

На рис. 1 представлены спектры люминесценции КТ $\mathrm{CdS} / \mathrm{TGA}$ в этанольном растворе, а также их смесей с дикетонатом европия при возбуждении излучением с длиной волны $375 \mathrm{~nm}$. Максимум полосы люминесценции КТ расположен в области $530 \mathrm{~nm}(2.34 \mathrm{eV})$. Поскольку максимум экситонного поглощения для КT CdS расположен в области $365 \mathrm{~nm}(3.40 \mathrm{eV})$, полуширина полосы люминесценции составляет $160 \mathrm{~nm}$, наблюдаемое свечение отнесено к рекомбинационному с участием донорно-акцепторных пар [49].

В спектре люминесценции дикетоната европия присутствует несколько узких пиков. Пик при $592 \mathrm{~nm}$ обусловлен переходами между термами ${ }^{5} D_{0} \rightarrow{ }^{7} F_{1}$, в области $615 \mathrm{~nm}-{ }^{5} D_{0} \rightarrow{ }^{7} F_{2}$, а при 653 и $702 \mathrm{~nm}-$ ${ }^{5} D_{0} \rightarrow{ }^{7} F_{3}$ и ${ }^{5} D_{0} \rightarrow{ }^{7} F_{4}$.

При введении этанольных растворов дикетоната европия в коллоидный раствор с формирующимися КT CdS наблюдали значительные изменения в спектре люминесценции (рис. 1). По мере увеличения концентрации КТ интенсивность люминесценции европия во всех полосах сначала растет, достигая максимума, а затем падает (рис. 1, врезка). Рост интенсивности люминесценции европия при этом достигает пяти раз. Одновременно с ростом концентрации КТ, но уже монотонно увеличивается интенсивность рекомбинационной люминесценции КТ. Отметим, что при используемых концентрациях растворов КТ CdS и дикетоната европия все возбуждающее излучение поглощалось компонентами пропорционально их относительной концентрации. Поэтому рост интенсивности люминесценции европия при увеличении содержания КТ $\mathrm{CdS}$, равно как и тушение люминесценции КТ дикетонатом европия, однозначно указывает на значительное взаимодействие между КТ $\mathrm{CdS}$ и ионами $\mathrm{Eu}^{3+}$.

На рис. 2, а представлены кривые затухания люминесценции $\mathrm{Eu}^{3+}$ на длине волны $615 \mathrm{~nm}$ как для чистого дикетоната европия, так и для смесей с КТ $\mathrm{CdS}$, записанные при постоянных условиях (время накопления, интенсивность возбуждения ит.д.). Поэтому суммирование всех фотонов под кривой затухания представляет интенсивность люминесценции. Все кривые описываются экспоненциальной функцией. Выделим два наиболее важных результата. Во-первых, по мере увеличения концентрации КТ $\mathrm{CdS}$ до $23 \%$ монотонно замедляется кинетика затухания люминесценции (рис. 2, a, кривые 1-4). При дальнейшем увеличении содержания $\mathrm{CdS}$ изменения в скорости затухания практически отсутствуют. По-видимому, при $23 \%$ содержании КT CdS в растворе все комплексы дикетоната европия находятся во взаимодействии с КТ. Зависимость времени жизни люминесценции от содержания КТ CdS представлена на врезке к рис. 1. Также при этой концентрации, повидимому, и все КТ находятся во взаимодействии с комплексами европия. В дальнейшем это заключение будет подтверждено данными о кинетике затухания люминесценции КT CdS.

Во-вторых, при увеличении концентрации КT CdS в растворе до $23 \%$ растет также интенсивность свечения европия в начальной точке кинетики затухания. Это указывает на увеличение эффективности возбуждения ионов европия в присутствии КT CdS. При дальнейшем увеличении концентрации КT CdS эффективность возбуждения люминесценции европия падает, что связано с ростом доли свободных КТ в растворе, которые по- 

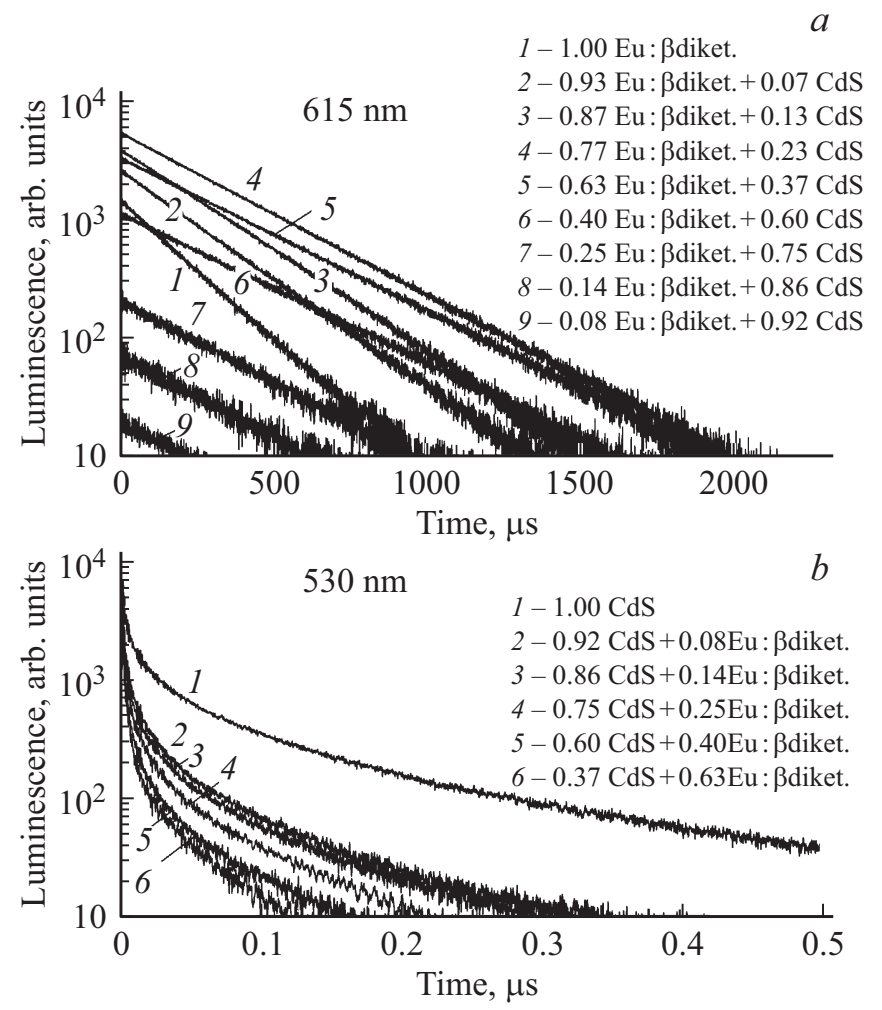

Рис. 2. Кривые затухания люминесценции: $a-$ в полосе люминесценции ионов европия $(615 \mathrm{~nm}) ; b-$ в полосе рекомбинационной люминесценции КТ $\mathrm{CdS}: \mathrm{Eu}^{3+}(530 \mathrm{~nm})$.

глощают возбуждающее излучение и выступают в роли фильтра.

В отличие от кривых затухания люминесценции $\mathrm{Eu}^{3+}$ для KT CdS при повышении концентрации дикетоната европия монотонно ускоряется кинетика затухания люминесценции в рекомбинационной полосе (рис. 2,b). При этом для значительной концентрации дикетоната европия, начиная с 40\%, падает интенсивность в начальной точке кинетики затухания люминесценции благодаря фильтр-эффекту от органического лиганда европия.

Таким образом, падение интенсивности и времени жизни люминесценции КT CdS при смешивании с дикетонатом европия, увеличение интенсивности и времени жизни люминесценции $\mathrm{Eu}^{3+}$ позволяют сделать вывод о легировании $\mathrm{KT} \mathrm{CdS}$ ионами $\mathrm{Eu}^{3+}$. Изменение времени жизни люминесценции $\mathrm{Eu}^{3+}$ указывает на изменение ближайшего окружения иона европия. Наиболее вероятны два вида подобных ассоциатов. Первый возникает при замене части молекул лиганда европия (молекулы дикетона) на молекулы тиогликолевой кислоты и образовании карбоксилатного комплекса. При этом ион $\mathrm{Eu}^{3+}$ присоединяется к карбоксильной группе тиогликолевой кислоты, адсорбированной на поверхности КТ, поскольку при синтезе образцов особое внимание было уделено удалению свободных молекул TGA из раствора. Строение такого комплекса можно представить в виде
$\mathrm{CdS} / \mathrm{TGA} / \mathrm{Eu}^{3+}$. Второй соответствует случаю адсорбции ионов $\mathrm{Eu}^{3+}$ на КТ $\mathrm{CdS}$ и встраивание их в приповерхностный слой КТ. В таком случае формируется структура типа ядро/оболочка КТ $\mathrm{CdS} / \mathrm{CdS}: \mathrm{Eu}^{3+}$, пассивированная как молекулами TGA, так и молекулами $\beta$-дикетона. Установление особенностей строения комплексов дикетоната европия с KT CdS является отдельной самостоятельной работой и будет осуществлено в будущем методом ИК спектроскопии.

Для сборки гибридных ассоциатов из сформированных КT CdS/TGA/Eu ${ }^{3+}$ и $\mathrm{CdS} / \mathrm{CdS}: \mathrm{Eu}^{3+}$ с молекулами $\mathrm{MB}^{+}$использован образец с относительной концентрацией КT $\mathrm{CdS}$ в растворе 0.37, который удобен тем, что весь дикетонат европия связан с КТ $\mathrm{CdS}$, о чем свидетельствует длительное время жизни люминесценции. С другой стороны, значительная доля КТ $\mathrm{CdS}$ в растворе также связана с дикетонатом европия, о чем свидетельствует ускоренная кинетика затухания люминесценции КT CdS по сравнению с чистыми КТ (рис. 1 и 2).

На рис. 3 представлены спектры поглощения растворов молекул $\mathrm{MB}^{+}$и его комплексов с KT CdS и дикетонатом европия. Форма и спектральное расположение (максимум около $655 \mathrm{~nm}$ ) полосы поглощения позволяют заключить, что молекулы красителя во всех случаях присутствуют только в мономерной форме. Наиболее важный результат заключается в увеличении на $10 \%$ полуширины спектров поглощения, что указывает на эффективную сборку гибридных ассоциатов $\mathrm{MB}^{+}$с КТ $\mathrm{CdS} / \mathrm{TGA} / \mathrm{Eu}^{3+}$ и $\mathrm{CdS} / \mathrm{CdS}: \mathrm{Eu}^{3+}$.

На рис. 4 представлены кривые затухания как в полосе рекомбинационной люминесценции, так и в полосе внутрицентровой люминесценции ионов $\mathrm{Eu}^{3+}$ при добавлении молекул $\mathrm{MB}^{+}$. Для обеих полос люминесценции при увеличении концентрации молекул $\mathrm{MB}^{+}$наблюдается ускорение затухания люминесценции. Для внутрицентровой люминесценции ионов $\mathrm{Eu}^{3+}$ все кривые затухания описываются экспоненциальной функцией с постоянными времени 320, 92, 51 и 21 мкс для чистых КТ и в комплексе с молекулами $\mathrm{MB}^{+}$в концентрациях $5 \cdot 10^{-6}$, $10^{-5}$ и $2.3 \cdot 10^{-5} \mathrm{~mol} / \mathrm{l}$. Для рекомбинационной люминесценции КТ характерна неэкспоненциальная кинети-

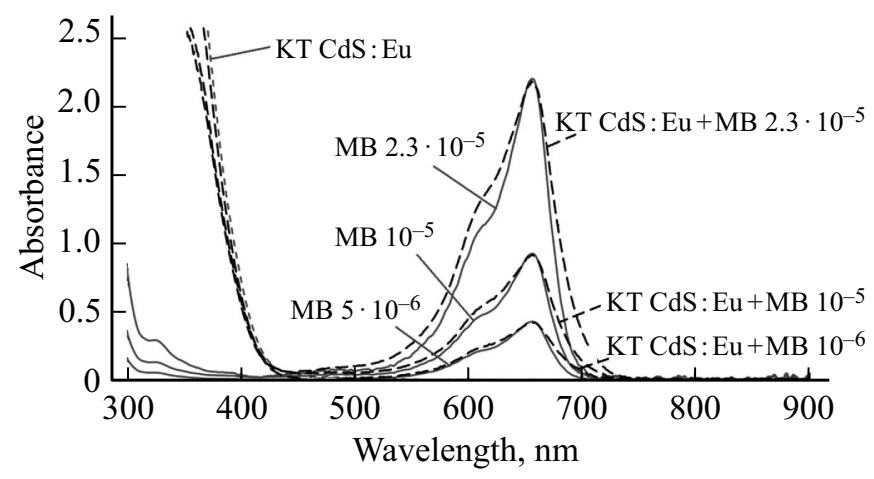

Рис. 3. Спектры поглощения раствора $\mathrm{MB}^{+}$и комплексов $\mathrm{MB}^{+}$с КT CdS и дикетоната европия. 


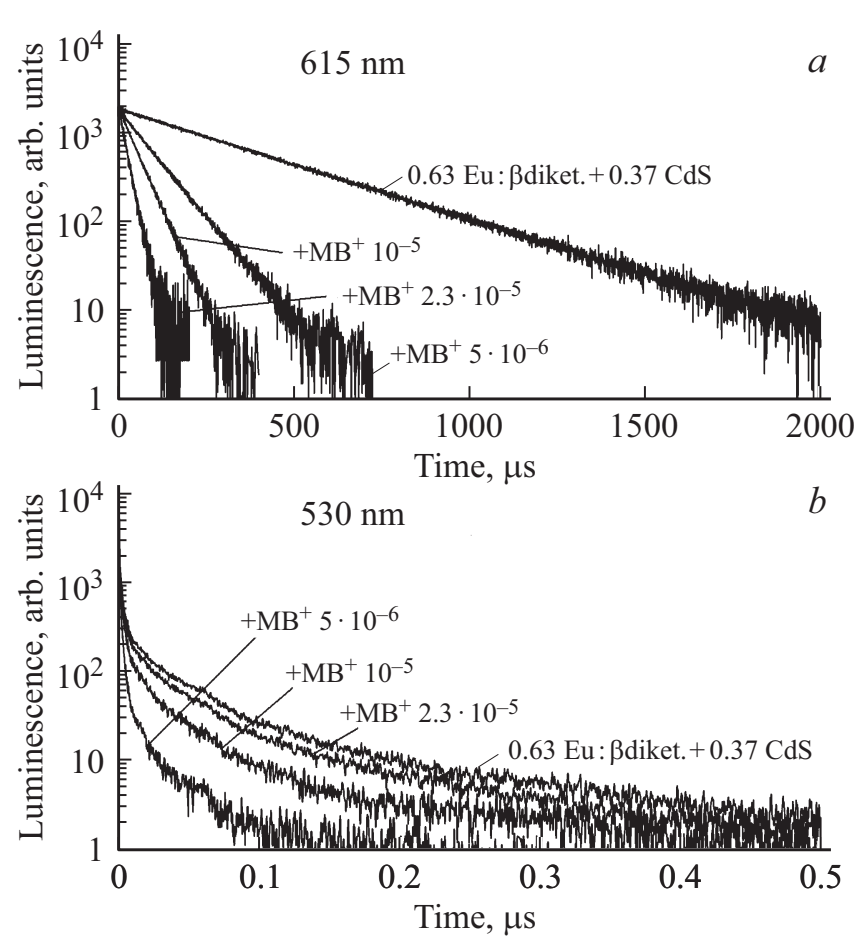

Pис. 4. Кинетика затухания люминесценции комплексов КТ $\mathrm{CdS}$ и дикетоната европия с $\mathrm{MB}^{+}: a-$ в полосе люминесценции ионов европия $(615 \mathrm{~nm}) ; b-$ в полосе рекомбинационной люминесценции КТ CdS.

ка затухания люминесценции, обусловленная донорноакцепторным механизмом свечения [49]. Среднее время жизни люминесценции КТ в рассматриваемом случае составило 2.2, 1.9, 1.5, 0.8 ns. Сокращение времени жизни для внутрицентровой люминесценции ионов $\mathrm{Eu}^{3+}$ было более чем 15-кратным, в то время как для рекомбинационной люминесценции эти изменения составили всего 2.7 раза. Поскольку сокращение времени жизни люминесценции $\mathrm{Eu}^{3+}$ и рекомбинационной полосы КТ $\mathrm{CdS}$ в присутствии молекул красителя совместно с обнаруженным разгоранием его флуоресценции являются признаками безызлучательного переноса энергии электронного возбуждения к красителю, то эффективность тушения донора энергии будет определяться интегралом перекрытия его люминесценции и поглощения красителя. В таком случае различие в эффективности тушения рекомбинационной и внутрицентровой люминесценции обусловлено взаимным расположением полосы поглощения красителя и полос люминесценции.

\section{Заключение}

На основании экспериментальных данных о возрастании интенсивности люминесценции ионов $\mathrm{Eu}^{3+}$ при легировании КT $\mathrm{CdS}$ ионами европия из комплекса $\mathrm{Eu}^{3+}$ с $\beta$-дикетоном (4,4,4-трифтор-1-(тиофен-2-ил)бутан-1,3дион (теноилтрифторацетон)) более чем в 5 раз, возникновении в спектре возбуждения внутрицентровой люминесценции $\mathrm{Eu}^{3+}$ полосы, совпадающей со спектром оптического поглощения КТ, а также двукратного увеличения времени жизни люминесценции $\mathrm{Eu}^{3+}$ сделан вывод о формировании в результате легирования структур типа ядро /оболочка $\mathrm{CdS} / \mathrm{CdS}: \mathrm{Eu}^{3+}$. При этом отмечается вероятность адсорбции дикетоната европия на интерфейсах КТ и формирования КТ CdS/TGA/Eu ${ }^{3+}$.

Получены спектральные закономерности, демонстрирующие безызлучательный перенос энергии от центров рекомбинационной люминесценции легированных КТ $\mathrm{CdS}$ к ионам $\mathrm{Eu}^{3+}$, проявляющиеся в тушении рекомбинационной люминесценции КТ и разгорании внутрицентровой люминесценции $\mathrm{Eu}^{3+}$, которые усиливаются с ростом концентрации дикетоната европия до $2 \mathrm{~mol} \%$. Отмечено также появление в спектре возбуждения полосы, совпадающей со спектром оптического поглощения КТ.

Сделан вывод о безызлучательном переносе энергии от центров рекомбинационной люминесценции легированных КТ CdS (в меньшей степени) и от ионов $\mathrm{Eu}^{3+}$ (в большей степени) на $\mathrm{MB}^{+}$.

Работа поддержана грантами РФФИ № 17-02-00748a. Исследования рентгеновской дифракции и просвечивающей электронной микроскопии выполнены в центре коллективного пользования научным оборудованием „Воронежского государственного университета“ (ЦКП НО ВГУ).

\section{Список литературы}

[1] Ye X., Zhuang $W$., Hu Y., He T., Huang X., Liao C., Zhong S., Xu Z., Nie H., Deng G. // J. Appl. Phys. 2009. V. 105. N 6. P. 064302. doi 10.1063/1.3086624

[2] Liang H., Zhang Q.J., Zheng Z.Q., Ming H., Li Z.C., Xu J., Chen B., Zhao H. // Opt. Lett. 2004. V. 29. N 5. P. 477. doi 10.1364/OL.29.000477

[3] Xie X., Gao N., Deng R., Sun Q., Xu Q., Liu X. // J. Am. Chem. Soc. 2013. V. 135. N 34. P. 12608. doi $10.1021 / \mathrm{ja} 4075002$

[4] Chen F., Bu W., Zhang S., Liu J., Fan W., Zhou L., Peng W., Shi J. // Adv. Funct. Mater. 2013. V. 23. P. 298. doi 10.1002/adfm.201201469

[5] Hoppe H.A. // Angew Chem. 2009. V. 48. N 20. P. 3572. doi 10.1002/anie.200804005

[6] Auzel F. // Chem. Rev. 2004. V. 104. N 1. P. 139. doi 10.1021/cr020357g

[7] Adya V.C., Mohapatra M., Bhide M.K., Natarajan V. // Mat. Sci. and Engin. B. 2016. V. 203. P. 35. doi 10.1016/j.mseb.2015.10.010

[8] Jia G., Huang Y., Song Y., Yang M., Zhang L., You H. // Eur. J. Inorg. Chem. 2009. V. 25. P. 3721. doi 10.1002/ejic.200900495

[9] Mendez M., Cesteros Y., Marsal L.F., Giguére A., Drouin D., Salagre P., Formentin P., Pallares J., Aguilo M., Diaz F., Carvajal J.J. // Inorg. Chem. 2012. V. 51. N 11. P. 6139. doi 10.1021/ic300108f

[10] Chandrashekar M., Nagabhushana H., Sharma S.C., Vidya Y.S., Anantharaju K.S., Prasad D., Prashantha S.C., Kavyashree D., Maiya P.S. // Mater. Res. Exp. 2015. V. 2. P. 045402. doi 10.1088/2053-1591/2/4/045402 
[11] Zhang X., Yang P., Wang D., Xu J., Li C., Gai S.I., Lin J. // Cryst. Growth Des. 2012. V. 12. N 1. P. 306. doi $10.1021 / \mathrm{cg} 201091 \mathrm{u}$

[12] Zou H., Wang Y., Gao F., Sheng Y., Zheng K., Zhou X., Song Y. // J. Alloys Compd. 2015. V. 622. P. 143. doi 10.1016/j.jallcom.2014.10.032

[13] Vidya Y.S., Anantharaju K.S., Nagabhushana H., Sharma S.C. // J. Alloys Compd. 2015. V. 619. P. 760. doi 10.1016/j.jallcom.2014.09.050

[14] Liu Y., Li X.-S., Hи J., Guo M., Liu W.-J., Feng Y.-M., Xie J.-R., Du G.-X. // Colloids and Surf. B: Biointerfac. 2015. V. 136. P. 721. doi 10.1016/j.colsurfb.2015.10.020

[15] Xu X.-Y., Yan B. // Sensors and Actuators B: Chem. 2016. V. 222. P. 347. doi 10.1016/j.snb.2015.08.082

[16] Rajamouli B., Sivakumar V. // J. Photochem. Photobiol. A: Chem. 2017. V. 347. P. 26. doi 10.1016/j.jphotochem.2017.07.008

[17] Stefan M., Leostean C., Pana O., Toloman D., Popa A., Perhaita I., Senila M., Marincas O., Barbu-Tudoran L. // Appl. Surf. Sci. 2016. V. 390. P. 248. doi 10.1016/j.apsusc.2016.08.084

[18] Sadhu S., Chowdhury P.S., Patra A. // J. Luminesc. 2007. V. 126. N 2. P. 387. doi 10.1016/j.jlumin.2006.08.087

[19] Zhang K., Yu Y., Sun S. // Appl. Surf. Sci. 2012. V. 258. N 19. P. 7658. doi 10.1016/j.apsusc.2012.04.114

[20] Zhou C., Song J., Zhang X., Sun L., Zhou L., Huang N., Gan Y., Chen M., Zhang W. // J. Nanosci. Nanotechnol. 2016. V. 16. N 4. P. 3848. doi 10.1166/jnn.2016.11789

[21] Pessoni H.V.S., Maia L.J.Q, Franco A. // Mat. Sci. in Semicond. Proc. 2015. V. 30. P. 135. doi 10.1016/j.mssp.2014.09.039

[22] Ehrhart G., Capoen B., Robbe O., Beclin F., Boy Ph., Turrell S., Bouazaoui M. // Opt. Mat. 2008. V. 30. N 10. P. 1595. doi 10.1016/j.optmat.2007.10.004

[23] Bao N., Liu Y., Li Z.-W., Yu H., Bai H.-t., Xia L., Feng D.-w., Zhang H.-b., Dong X.-t., Wang T.-y., Han J., Wu R.-y., Zhang Q. // J. Luminesc. 2016. V. 177. P. 409. doi 10.1016/j.jlumin.2016.05.025

[24] Orlova A.O., Gromova Yu.A., Maslov V.G., Prudnikau A.V., Artemyev M.V., Fedorov A.V., Baranov A.V. // J. Appl. Phys. 2013. V. 113. P. 214305. doi $10.1063 / 1.4809645$

[25] Вишератина А.К., Алисова И.В., Кунделев Е.В., Орлова А.О., Маслов В.Г., Фёдоров А.В., Баранов А.В. // Опт. и спектр. 2015. Т. 119. № 5. С. 707; Visheratina A.K., Alisova I.V., Kundelev E.V., Orlova A.O., Maslov V.G., Fedorov A.V., Baranov A.V. // Opt. Spectrosc. 2015. V. 119. N 5. P. 733. doi 10.1134/S0030400X15110259.

[26] Дададжсанов Д.Р., Мартыненко И.В., Орлова А.О., Маслов В.Г., Фёдоров А.В., Баранов А.В. // Опт. и спектр. 2015. Т. 119. № 5. C. 712; Dadadzhanov D.R., Martynenko I.V., Orlova A.O., Maslov V.G., Fedorov A.V., Baranov A.V. // Opt. Spectrosc. 2015. V. 119. № 5. P. 738. doi 10.1134/S0030400X15110053.

[27] Smirnov M.S., Ovchinnikov O.V., Shatskikh T.S., Vitukhnovsky A.G., Ambrozevich S.A., Perepelitsa A.S. // J. Luminesc. 2014. V. 156. P. 212.

doi 10.1016/j.jlumin.2014.08.026
[28] Овчинников О.В., Смирнов М.С., Шапиро Б.И., Шатских T.C., Латышев А.H., Pham Thi Hai Mien, Хoxлов В.Ю. // Опт. и спектр. 2013. Т. 115. № 3. С. 389; Ovchinnikov O.V., Smirnov M.S., Shapiro B.I., Shatskikh T.S., Latyshev A.N., Pham Thi Hai Mien, Khokhlov V.Yu. // Opt. Spectrosc. 2013. V. 115. N 3. P. 340. doi 10.1134/S0030400X1309018X

[29] Ovchinnikov O.V., Smirnov M.S., Shatskikh T.S., Khokhlov V.Yu., Shapiro B.I., Vitukhnovsky A.G., Ambrozevich S.A. // J. Nanopart. Res. 2014. V. 16. N 2. P. 2286. doi 10.1007/s11051-014-2286-5

[30] Овчинников О.В., Смирнов М.С., Шапиро Б.И., Дедикова А.О., Шатских Т.С. // Опт. и спектр. 2015. Т. 119. № 5. C. 718; Ovchinnikov O.V., Smirnov M.S., Shapiro B.I,, Dedikova A.O., Shatskikh T.S. // Opt. Spectrosc. 2015. V. 119. N 5. P. 744. doi 10.1134/S0030400X1511017X

[31] Smirnov M.S., Ovchinnikov O.V., Dedikova A.O., Shapiro B.I., Vitukhnovsky A.G., Shatskikh T.S. // J. Luminesc. 2016. V. 176. P. 77. doi 10.1016/j.jlumin.2016.03.015

[32] Ovchinnikov O.V., Kondratenko T.S., Grevtseva I.G., Smirnov M.S., Pokutnyi S.I. // J. Nanophotonics. 2016. V. 10. N 3. P. 033505. doi 10.1117/1.JNP.10.033505

[33] Кондратенко Т.С., Овчинников О.В., Гревцева И.Г., Смирнов М.С. // Рос. нанотех. 2016. Т. 11. № 1-2. C. 61; Kondratenko T.S., Ovchinnikov O.V., Grevtseva I.G., Smirnov M.S. // Nanotechnol. in Russia. 2016. V. 11. N 1-2. P. 85. doi 10.1134/S1995078016010080

[34] Овчинников О.В., Гревцева И.Г., Кондратенко Т.С., Смирнов М.С., Евтухова А.В. // ЖПС. 2016. Т. 83. № 3. C. 450; Ovchinnikov O.V., Grevtseva I.G., Kondratenko T.S., Smirnov M.S., Evtukhova A.V. // J. Appl. Spectrosc. 2016. V. 83. N 3. P. 442. doi $10.1007 / \mathrm{s} 10812-016-0308-\mathrm{z}$

[35] Смирнов М.С. // Опт. и спектр. 2017. Т. 123. № 5. С. 704; Smirnov M.S. // Opt. Spectrosc. 2017. V. 123. N 5. P. 705. doi 10.1134/S0030400X17090284

[36] Ермолаев В.Л., Свешникова Е.Б., Шахвердов Т.А. // Успехи химии. 1976. Т. 45. Вып. 10. С. 1753; Ermolaev V.L., Sveshnikova E.V., Shakhverdov T.A. // Russ. Chem. Rev. 1976. V. 45. N 10. P. 896. doi 10.1070/RC1976v045n10ABEH002732

[37] Ермолаев В.Л., Шахвердов Т.А. // Опт. и спектр. 1969. T. 26. № 5. C. 845 .

[38] Ермолаев В.Л., Шахвердов Т.А. // Опт. и спектр. 1971. T. 30. B. 4. C. 648.

[39] Шахвердов Т.А., Ермолаев В.Л. // Опт. и спектр. 1972. T. 33. B. 5. C. 941.

[40] Ермолаев В.Л., Бодунов Е.Н., Свешникова Е.Б., Шахвердов T.A. Безызлучательный перенос энергии электронного возбуждения. Л.: Наука, 1977. 311 с.

[41] Шахвердов Т.А. // Изв. АН СССР. Сер. физ. 1972. Т. 36. № 5. C. 1018.

[42] Дударь С.С., Свешникова Е.Б., Ермолаев В.Л. // Опт. и спектр. 2008. T. 104. № 2. C. 262; Dudar S.S., Sveshnikova E.B., Ermolaev V.L. // Opt. Spectrosc. 2008. V. 104. N 2. P. 225. doi 10.1007/s11449-008-2013-х

[43] Ермолаев В.Л., Свешникова Е.Б. // Успехи химии. 2012. T. 81. C. 769; Ermolaev V.L., Sveshnikova E.B. // Russ. Chem. Rev. 2012. V. 81. N 9. P. 769. doi 10.1070/RC2012v081n09ABEH004259 
[44] Миронов Л.Ю., Свешникова Е.Б., Ермолаев В.Л. // Опт. и спектр. 2014. Т. 117. № 6. С. 923; Mironov L.Y., Sveshnikova E.B., Ermolaev V.L. // Opt. Spectrosc. 2014. V. 117. N 6. P. 896. doi 10.1134/S0030400X14120169

[45] Миронов Л.Ю., Свешникова Е.Б., Ермолаев В.Л. // Опт. и спектр. 2014. Т. 116. № 6. С. 1009; Mironov L.Yu., Sveshnikova E.B., Ermolaev V.L. // Opt. Spectrosc. 2014. T. 116. N 6. P. 933. doi 10.1134/S0030400X14060162

[46] Миронов Л.Ю., Свешникова Е.Б., Ермолаев В.Л. // Опт. и спектр. 2015. Т. 119. № 1. С. 80; Mironov L.Y., Sveshnikova E.B., Ermolaev V.L. // Opt. Spectrosc. 2015. V. 119. N 1. P. 77. doi 10.1134/S0030400X15070188

[47] Смирнов М.С., Овчинников О.В., Нассра Амир Разуки Хазаль, Звягин А.И. // Неорган. матер. 2018. Т. 54. № 5. C. 431; Smirnov M.S., Ovchinnikov O.V., Nassra Amir Razuki Khazal, Zvyagin A.I. // Inorg. Mater. 2018. T. 54. N 5. P. 413. doi 10.1134/S002016851805014X

[48] Кондратенко Т.С., Смирнов М.С., Овчинников О.В., Шабуня-Клячковская Е.В., Мачукович А.С., Звягин А.И., Винокур Я.А. // ФТП. 2018. Т. 52. № 9. С. 1015; Kondratenko T.S., Smirnov M.S., Ovchinnikov O.V., Shabunya-Klyachkovskaya E.V., Matsukovich A.S., Zvyagin A.I., Vinokur Y.A. // Semiconductors. 2018. V. 52. N 9. P. 1015.

[49] Ovchinnikov O.V., Smirnov M.S., Korolev N.V., Golovinski P.A., Vitukhnovsky A.G. // J. Luminesc. 2016. V. 179. P. 413. doi 10.1016/j.jlumin.2016.07.016 